disease activity, 550 (23.9\%) had moderate disease activity, 1139 (49.5\%) considered as mild disease activity and $557(24.2 \%)$ were considered to be in remission.

Conclusions: This study has created a database and registry from which important data has been derived. Majority of the patients are being managed sub-optimally, most likely due to limited access to advanced therapies in prominent rheumatological diseases that are intrinsically active and respond modestly to conventional DMARDs and therapy. Further analysis is ongoing

Disclosure of Interest: None declared

DOI: 10.1136/annrheumdis-2018-eular.6326

\section{AB1342 RHEUMATIC DISEASES PREVALENCE AND QUALITY OF LIFE IN SARAGURO INDIGENOUS POPULATIONS OF ECUADOR: A CROSS-SECTIONAL COMMUNITY-BASED STUDY}

S. Guevara-Pacheco ${ }^{1,2}$, A. Feican-Alvarado ${ }^{3}$, W. Valdiviezo-Vicuña ${ }^{4}$, G. MolinaAlvarado $^{5}$, N. Ortega-Mendoza ${ }^{5}$, J. Delgado-Pauta ${ }^{3}$, M. Montaleza-Neira $^{3}$, L. Chimbo-Pullaguari' ${ }^{6}$ M. Hernandez ${ }^{7}$, R. Cervera-Segura ${ }^{7}$, L.H. Sanin ${ }^{8}$, I. Pelaez Ballestas ${ }^{9}$, on behalf of GLADERPO. ${ }^{1}$ Medicine Faculty, Universidad de Cuenca, Cuenca, Ecuador, ${ }^{2}$ Medicine Postgraduate, Universitat de Barcelona, Barcelona, Spain; ${ }^{3}$ Universidad de Cuenca, Cuenca; ${ }^{4}$ Hospital Homero Castanier, Azogues; ${ }^{5}$ Hospital Jose Carrasco Arteaga, Cuenca; ${ }^{6}$ Distrito de Salud, Saraguro, Ecuador, ${ }^{7}$ Hospital Clinic, Barcelona, Spain; ${ }^{8}$ Universidad Autonoma de Chihuahua, Chihuahua; ${ }^{9}$ Hospital General de Mexico, Mexico City, Mexico

Background: Rheumatic diseases are more prevalent and aggressive in indigenous population groups, in which providing medical attention poses a challenge for the rheumatologist.

Objectives: To estimate the prevalence of musculoskeletal (MSK) disorders and rheumatic diseases in the Saraguro indigenous people and their impact on the quality of life.

Methods: Cross-sectional analytical study carried out in the community of Saraguro using the COPCORD methodology. Mixed and randomised sampling techniques were employed. The following validated questionnaires were administered 1. Screening for musculoskeletal (MSK) disorders and rheumatic diseases. 2. A sociodemographic questionnaire. 3. A functional capacity questionnaire (HAQ-DI) and an instrument to measure workload and repetitive movements. 4. Quality of life (EQ-5D3L). Cases with MSK disorders were reviewed by rheumatologists within the community.

Results: A total of 2687 individuals over 18 years of age participated, with an average age of 44 (SD 19.9) years; 1690 (62.9\%) were women, $872(32.4 \%)$ were Kwichua speakers; 2108 (78.4\%) were employed, of these $32.5 \%$ were farm workers. MSK pain was reported in 1244 (46.3\%); pain was severe in $448(36 \%)$; $868(69.7 \%)$ used some medical treatment and $1013(81.4 \%)$ used traditional medicine. The most prevalent self-reported comorbidities were anxiety $(55.5 \%)$ and depression (46.8\%). Rheumatic diseases were diagnosed in 861/1244 $(69.2 \%)$, with the following most prevalent conditions: Low back pain $9.3 \%$, hand osteoarthritis $7.2 \%$, knee osteoarthritis $6.5 \%$, RRPS (rheumatic regional pain syndrome) $5.8 \%$, fibromyalgia $1.8 \%$, rheumatoid arthritis (RA) $1.3 \%$. Disability (HAQ $>0.8$ ) was observed in 356 (28.6\%), whereas loading and pushing objects heavier than $20 \mathrm{~kg}$ and shaking hands was significantly associated with MSK pain. The regression models showed a significant association with a lower quality of life in those with lower education levels $(\mathrm{OR}=0.89 ; 95 \% \mathrm{Cl} 0.88$ to $0.91, \mathrm{p}<0.001)$, physically demanding jobs (OR=0.54;95\% $\mathrm{Cl} 0.42$ to $0.69, \mathrm{p}<0.001)$, cooking with firewood $(\mathrm{OR}=1.55 ; 95 \% \mathrm{Cl} 1.05$ to $2.30, \mathrm{p}=0.02)$, high blood pressure (OR=2.31; $95 \% \mathrm{Cl} 1.73$ to $3.10, \mathrm{p}<0.001)$, and rheumatic diseases, especially $\mathrm{RA}(\mathrm{OR}=5.52$; $95 \% \mathrm{Cl} 2.48$ to $12.27, \mathrm{p}<0.001)$ and hands $\mathrm{OA}(\mathrm{OR}=2.05 ; 95 \% \mathrm{Cl} 1.44$ to 2.91 , $\mathrm{p}<0.001)$. One finding is that having RA was associated with cooking with firewood, and that smoking was almost nonexistent in this population. This suggests that wood smoke pollutants play a similar role to that described with tobacco smoke.

Conclusions: A high prevalence of MSK disorders, rheumatic diseases and RA was found. The prevalence of rheumatic diseases was associated with a lower education level, cooking with firewood, and physically demanding jobs. The greatest impact on the quality of life in all dimensions was on the individuals with RA and hand $O A$.

Acknowledgements: Funding: Research Dept. Universidad de Cuenca, Ecuador

Disclosure of Interest: None declared

DOI: 10.1136/annrheumdis-2018-eular.4857

\section{$\mathrm{AB} 1343$ \\ PREVALENCE OF AUTOIMMUNE DISEASES IN CATALONIA: A POPULATION BASED STUDY USING A PUBLIC BIG DATA ANALYTICS (PADRIS)}

A. Sisó-Almirall ${ }^{1,2,3}$, B. Kostov ${ }^{1,2,3}$, E. Martínez Carbonell ${ }^{4}, \underline{\text { S. Retamozo }}^{5,6,7}$, A. Flores-Chavez ${ }^{7,8,9}$, S. González-Martínez ${ }^{1,2,3}$, P. Brito-Zerón ${ }^{7}$, A. Dedéu Baraldés $^{4}$, J. Benavent Àreu ${ }^{1,2,3}$, M. Ramos-Casals ${ }^{2,7,10}$. ${ }^{1}$ Consorci d'Atenció Primària de Salut Barcelona Esquerre, CAPSBE; ${ }^{2}$ Departament de Medicina, Universitat de Barcelona; ${ }^{3}$ Grup de Recerca Transversal en Atenció Primària, IDIBAPS, Barcelona; ${ }^{4}$ Agency for Health Quality and Assessment of Catalonia (AQUAS), Ministry of Health, Catalonia, Spain; ${ }^{5}$ Instituto De Investigaciones En Ciencias De La Salud (INICSA), Universidad Nacional de Córdoba (UNC), Consejo Nacional de Investigaciones Científicas y Técnicas (CONICET), Córdoba; ${ }^{6}$ Hospital Privado Universitario de Córdoba, IUCBC, Cordoba, Argentina; ${ }^{7}$ Laboratory of Autoimmune Diseases Josep Font, IDIBAPS-CELLEX, Barcelona, Spain; ${ }^{8}$ Programa de Doctorado en Ciencias Médicas, Centro Universitario de Investigaciones Biomédicas (CUIB), Universidad de Colima, Colima; ${ }^{9}$ Unidad de Investigación Biomédica 02, Unidad de Investigación en Epidemiología Clínica, Centro Médico Nacional de Occidente (CMNO), Instituto Mexicano del Seguro Social (IMSS), Hospital de Especialidades, Guadalajara, Mexico; ${ }^{10}$ Department of Autoimmune Diseases, ICMiD, Hospital Clínic, Barcelona, Spain

Objectives: To analyse the prevalence of autoimmune diseases (ADs) in Catalonia by using a public big data program (Public Data Analysis for Health Research and Innovation Program, PADRIS)

Methods: We used the health insurance database of the Catalan National Health Insurance $(\mathrm{CNHI})$ which includes all catalan population registered as insured population in 2016. The sample included 7,483,761 inhabitants. ADs were identified according to the corresponding International Classification of Diseases, Ninth Revision, Clinical Modification (ICD-9-CM) codes. A total of 33 autoimmune diseases were analysed classified in 4 main categories: rheumatic, systemic, organspecific and immunodeficiency/autoinflammatory. The prevalence of ADs was calculated as the number of ADs patients divided by the total $\mathrm{CNHI}$ beneficiaries in the same year (rate per 100000 persons, 95\% confidence intervals - $\mathrm{Cl}$-)

Results: The overall prevalence of ADs was 1202 per 100000 persons $(95 \% \mathrm{Cl}$ $1,194-1,209)$; the prevalence was $1455(95 \% \mathrm{Cl} 1,443-1,467)$ in women and 939 $(95 \% \mathrm{Cl} 929-949)$ in men. ADs were classified as organ-specific $(43 \%)$, systemic $(33 \%)$, rheumatic $(23 \%)$ and immunodeficiency/autoinflammatory $(1 \%)$ autoimmune diseases. The ADs with the highest prevalence rates included psoriasis (282 cases per 100,000, 95\% Cl 278-286), rheumatoid arthritis (RA) (178 cases per $100,000,95 \% \mathrm{Cl} 175-181$ ), polymyalgia rheumatic (98 cases per 100,000, 95\% Cl 96-101), spondyloarthropathies (92 cases per 100,000, 95\% Cl 90-94), systemic lupus erythematosus (SLE) (68 cases per $100,000,95 \% \mathrm{Cl} 66-70)$ and Sjögren's syndrome (59 cases per 100,000, 95\% Cl 57-61). In 26 (79\%) of the 33 ADs, the female:male ratio was higher than 1; the highest ratios were reported for Sjögren's syndrome (10.5:1), primary biliary cholangitis (5.8:1), SLE (5.4:1), sys temic sclerosis (3.4:1) and rheumatoid arthritis (2.6:1). An enhanced prevalence of ADs was reported in Southern regions (1225 cases per 100000 persons in Barcelona/Tarragona regions -CI95\% 1,216-1,233- vs 1075 cases per 100000 persons in Girona/Lleida regions -Cl95\% 1,056-1,093-, p<0.001).

Conclusions: Nearly 90000 catalans are classified as having an autoimmune disease, representing a prevalence of $1.2 \%$ of the total catalan population, a rate which reaches $1.5 \%$ in women. The highest frequencies are reported for psoriasis $(0.28 \%)$, rheumatoid arthritis $(0.18 \%)$, polymyalgia rheumatica $(0.10 \%)$, spondyloarthropathies $(0.09 \%)$, lupus $(0.07 \%)$ and Sjögren syndrome $(0.06 \%)$.

Disclosure of Interest: None declared

DOI: 10.1136/annrheumdis-2018-eular.5974

\section{AB1344 PRESENCE OF ECHOCARDIOGRAPHIC CRITERIA FOR HFPEF MULTIPLIES THE RISK FOR DEATH AND CARDIOVASCULAR EVENTS IN PATIENTS WITH RHEUMATIC DISEASES}

S. Kleinert ${ }^{1,2}$, C. Morbach ${ }^{3}$, H.-P. Tony ${ }^{2}$, C.E. Angermann ${ }^{4}$, S. Stoerk ${ }^{3}$,

M. Breunig ${ }^{3}{ }^{1}$ Praxisgemeinschaft Rheumatologie - Nephrologie, Erlangen; ${ }^{2}$ Dept. of Medicine II, Rheumatology/Clinical Immunology; ${ }^{3}$ Comprehensive Heart Failure Center and Dept. of Medicine I, Würzburg; ${ }^{4}$ Comprehensive Heart Failure Center, University Hospital of Würzburg, Würzburg, Germany

Background: Patients with rheumatic diseases (RD) have an increased risk for cardiovascular (CV) disease and heart failure (HF). Clinical assessment of HF signs and symptoms in RD is often limited by functional impairment.

Objectives: We investigated the prognostic value of echocardiographic and neurohormonal criteria for HF with preserved ejection fraction (HFpEF) in patients with RD.

Methods: This prospective, single-centre study included consecutive RD outpatients considered at increased risk for CV events according to ESC score ( $\geq 3 \%)$ pathological ECG, or elevated NTproBNP ( $>200 \mathrm{pg} / \mathrm{mL}$ ) as published by this group*. Clinical assessment and transthoracic echocardiography according to 